\title{
Monocyte Chemoattractant Protein-1 as a Diagnostic Marker for Detection of Hepatocellular Carcinoma in Egypt
}

\author{
Sherif M. Galal ${ }^{1}$, Nermin Raafat ${ }^{2}$ \\ Departments of Tropical Medicine ${ }^{1}$ and Medical Biochemistry ${ }^{2}$ \\ Faculty of Medicine, Zagazig University, Egypt.
}

Corresponding Author Sherif M. Galal

Mobile:

$+201221053975$

E mail: dsherifgalal@yahoo. com

Key words: HCC, AFP, MCP-1
Background and study aim: Hepatocellullar carcinoma (HCC) is usually diagnosed at advanced stage resulting in limited therapeutic options and poor prognosis. The role of alphafetoprotein (AFP) in the diagnosis of HCC is controversial. Here, we investigated the role of Monocyte Chemoattractant Protein -1 (MCP-1), a serum biomarker, alone or in combination with AFP for detection of HCC.

Patients and Methods: 116 patients with liver cirrhosis were included. The patients were divided into 2 groups: HCC group included 58 patients with HCC and nonHCC patients as a control group included 58 patients with no evidence of hepatic focal masses. Routine laboratory investigations, AFP, MCP-1, pelviabdominal ultrasonography (US) and

\section{INTRODUCTION}

Hepatocellular carcinoma (HCC) is the second leading cause of cancerrelated deaths worldwide. The incidence of HCC has been increased both in the United States and abroad with approximately 750,000 new cases of liver cancer reported per year $[\mathbf{1 , 2}]$. Egypt has rising rates of $\mathrm{HCC}$ and being a unique nature of liver disease that presents questions regarding the etiology of HCC; the currently increasing incidence of HCC in Egyptians may be due to shift of the relative importance of hepatitis $\mathrm{C}$ virus $(\mathrm{HCV})$ as primary risk factors [3].

$\mathrm{HCC}$ is usually diagnosed at advanced stage resulting in limited therapeutic options and poor prognosis. The identification of biomarkers is an important issue since such markers could facilitate detection of HCC. triphasic computed tomography (CT) scan were performed in all patients.

Results: It was found that MCP-1 at a cut-off value $>0.390 \mathrm{ng} / \mathrm{ml}$ has a sensitivity of $75.8 \%$ and specificity of $88.3 \%$ with AUROC 0.916; But AFP at a cut-off value $>20 \mathrm{ng} / \mathrm{ml}$ has a sensitivity of $86.5 \%$ and specificity of $96.4 \%$ with AUROC 0.924 , while combined (AFP+ MCP-1) at a cutoff value $>23.390 \mathrm{ng} / \mathrm{ml}$ has a higher sensitivity $(96.5 \%)$ specificity of $100 \%$ with AUROC 0.995.

Conclusion: Monocyte Chemoattractant Protein-1 (MCP-1) can be identified as an adjuvant biomarker for HCC detection. Combined (AFP+MCP-1) showed higher diagnostic ability than MCP-1 alone or AFP alone in HCC detection.

Furthermore, such biomarkers could display potential therapeutic targets for HCC [4].

The most commonly used serum marker of HCC is Alpha-fetoprotein (AFP), which has a reported sensitivity of $49 \%$ to $71 \%$ and specificity of $49 \%$ to $86 \%$ in HCCs smaller than $5 \mathrm{~cm}$. Its levels are influenced by tumor size and aggressiveness, as well as by the etiology and activity of the liver disease $[\mathbf{5 , 6 , 7 ]}$. Approximately one-third of early-stage HCC patients with small tumors $(<5 \mathrm{~cm})$ have normal levels of AFP [8]. Thus, clinicians are dissatisfied with AFP as a marker due to its high false-positive and false-negative rates. Consequently there is urgent clinical need to identify new biomarkers that will improve new diagnosis of early HCC over the current screening practice of serum AFP measurements. [9]. 
The Monocyte Chemoattractant Protein-1 (MCP-1), is a small cytokine that belongs to the CC chemokine family. It is a potent chemotactic factor for monocytes. MCP-1is one of the key chemokines that regulate migration and infiltration of monocytes/macrophages It was found that MCP-1was significantly elevated in patients with resectable HCC compared to non-HCC chronic hepatitis B (HBV) carriers [10].. Here, we investigated the role of MCP-1, a serum biomarker, alone or in combination with AFP for detection of HCC.

\section{PATIENTS AND METHODS}

This comparative case-control study was conducted in Tropical Medicine Department in cooperation with Medical Biochemistry Department, Zagazig University, Egypt, during the period from January 2015 to December 2015 and included 116 cirrhotic patients. The patients were divided into 2 groups:

Group I (HCC group): Included 58 cirrhotic patients with HCC (48 males and 10 females) diagnosed by triphasic computed tomography (CT) scan.
Group II (Non-HCC patients): Included 58 cirrhotic patients (46 males and 12 females) with no evidence of hepatic focal masses as a control group.

\section{Enrollment criteria:}

Patients with liver cirrhosis, with or without HCC were included. Diagnosis of liver cirrhosis was based on clinical, laboratory and imaging tests, and liver biopsy if present. Patients with cirrhosis and focal hepatic lesions on ultrasound with normal AFP were subjected to triphasic CT. The diagnosis of HCC by triphasic CT-scan showing was based on typical criteria for HCC (early enhancement during arterial phase followed by washout of contrast in porto-venous and delayed phases).

\section{Exclusion criteria:}

Patients with other malignancies elsewhere and patients with Child- Pugh class $C$ were excluded.

\section{Methods:}

Patients were subjected to:

1. Detailed history taking.

2. Thorough clinical examination.

Child-Turcotte-Pugh classing was evaluated for each patient (Table I).

Table (I): Child-Pugh-Turcotte criteria

\begin{tabular}{|l|c|c|c|}
\hline & 1 Point & 2 Points & 3 Points \\
\hline Albumin (g/dl) & $>3.5$ & $2.8-3.5$ & $<2.8$ \\
\hline Bilirubin (mg/dL) & $<2$ & $2-3$ & $>3$ \\
\hline Ascites & None & Minimal & Moderate \\
\hline Encephalopathy & None & Grade 1-2 & Grade 3-4 \\
\hline PT (second prolonged) & $<4$ & $4-6$ & $>6$ \\
INR & $<1.7$ & $<1.7-2.3$ & $>2.3$ \\
\hline
\end{tabular}

PT; prothormbin time INR, International Normalizing Ratio

Class A: 5-6 points; class B: 7-9 points; class C: 10-15 points

3. Routine laboratory investigations (complete blood counts, liver and kidney profiles, coagulation profile).

4. Alpha-feto protein (AFP): It was determined by ELISA Kit provided by RayBiotech, Inc., the catalogue no ELH-AFP.

5. Monocyte Chemoattractent Protein -1 (MCP1): It was determined by ELISA Kit provided by Biospes Comany, the catalogue no BEK1142.

This kitwasbased on sandwich enzyme-linked immune-sorbentassay technology.Anti-MCP-1 polyclonal antibody was pre-coatedonto 96-well plates. And the biotin conjugated anti-MCP-
1 polyclonal antibody was used as detection antibodies. The standards, test samples and biotin conjugated detection antibody were added to the wells subsequently, and wash with wash buffer. Avidin-Biotin-Peroxidase Complex was added and unbound conjugates were washed away with wash buffer. TMB substrates were used to visualize HRP enzymatic reaction. TMB was catalyzed by HRP to produce a blue color product that changed into yellow after adding acidic stop solution. The density of yellow is proportional to the MCP-1 amount of sample captured in plate. Read the O.D. absorbance at $450 \mathrm{~nm}$ in a micro-plate reader, and then the concentration of MCP-1 can be calculated [11]. 
6. Pelvi-abdominal ultrasonography (esaote MyLab20Plus).

7. Abdominal triphasic CT scan: Diagnosis of HCC was based on typical criteria; hyper enhancement in the arterial phase with rapid wash out in both portal and delayed phases.

\section{Statistical analysis:}

Data were checked, entered and analyzed using SPSS version 19 for data processing and statistic. Data were expressed as mean $\pm \mathrm{SD}$ for quantitative variable, number and percentage for qualitative one. Chi-squared $\left(\mathrm{X}^{2}\right)$ or student " $t$ " test were used when appropriate. $\mathrm{P}<0.05$ was considered significant.

\section{RESULTS}

- In this study, no statistical significant differences were observed among both studied groups with respect to the following baseline characteristics: patients' sex and Child-Pugh class. While there was statistically significant difference among both studied groups as regard age $(\mathrm{P}=0.003)$. Most of patients were older in HCC group (57.86 \pm 5.73$)$ (Table 1)

- As regard tumor markers, there was statistically significant higher values of both AFP and
MCP-1 (374.16 \pm 282.77 and $0.703 \pm 0.360$ respectively) among patients of HCC group ( $\mathrm{P}$ $<0.001$ ) (Table 2).

- Regarding correlation between serum concentrations of AFP, MCP-1 and study parameters in HCC patients, there was no correlation as regard age and laboratory parameters. While, there was statistically significant correlation between tumor size (in $\mathrm{cm})$ and both MCP-1 $(\mathrm{P}<0.001)$ and AFP $(\mathrm{P}=$ 0.030) (Table 3).

- Concerning diagnostic performance of both serum MCP-1and serum AFP, either alone or in combination, in prediction of $\mathrm{HCC}$, it was found that MCP-1 at a cut-off value $>0.390$ $\mathrm{ng} / \mathrm{ml}$ has a sensitivity of $75.8 \%$ and specificity of $88.3 \%$ with AUROC 0.916 ; and AFP at a cut-off value $>20 \mathrm{ng} / \mathrm{ml}$ has a sensitivity of $86.5 \%$ and specificity of $96.4 \%$ with AUROC 0.924 , while combined (AFP+MCP-1) at a cut-off value $>23.390 \mathrm{ng} / \mathrm{ml}$ has a higher sensitivity (96.5\%) and specificity (100\%) with AUROC 0.995. Therefore, the diagnostic performance of combined (AFP+MCP-1) is more valuable than MCP-1 alone or AFP alone (Table 4 and Fig. 1).

Table (1): Baseline characteristics among both studied groups

\begin{tabular}{|c|c|c|c|c|c|c|}
\hline & \multicolumn{2}{|c|}{$\begin{array}{c}\text { (HCC patients) } \\
(\mathrm{n}=58)\end{array}$} & \multicolumn{2}{|c|}{$\begin{array}{c}\text { (Non-HCC patients) } \\
(n=58)\end{array}$} & $\mathbf{t}$ & P-value \\
\hline Age (Mean \pm SD) & \multicolumn{2}{|c|}{$57.86 \pm 5.73$} & \multicolumn{2}{|c|}{$53.68 \pm 4.37$} & 3.116 & 0.003 \\
\hline & No & $\%$ & No & $\%$ & $\mathbf{X}^{2}$ & P-value \\
\hline \multicolumn{5}{|l|}{ Gender } & \multirow{3}{*}{0.112} & \multirow{3}{*}{0.738} \\
\hline Male & 48 & $82.8 \%$ & 46 & $79.3 \%$ & & \\
\hline Female & 10 & $17.2 \%$ & 12 & $20.7 \%$ & & \\
\hline \multicolumn{5}{|l|}{ Child-Pugh Class } & \multirow{3}{*}{0.293} & \multirow{3}{*}{0.588} \\
\hline Child A & 38 & $65.5 \%$ & 34 & $58.6 \%$ & & \\
\hline Child B & 20 & $34.5 \%$ & 24 & $41.4 \%$ & & \\
\hline
\end{tabular}

$\mathrm{P}<0.05$; significant and $\mathrm{P}<0.001 ;$ highly significant

Table (2): Comparison between both studied groups as regard tumor markers

\begin{tabular}{|c|c|c|c|c|}
\hline Tumor markers & $\begin{array}{l}\text { HCC patients } \\
(\mathrm{N}=58)\end{array}$ & $\begin{array}{c}\text { Non-HCC patients } \\
(\mathrm{N}=58)\end{array}$ & Test & P-value \\
\hline AFP (ng/ml) & & & \multirow{3}{*}{$-6.470 \bullet$} & \multirow{3}{*}{$<0.001$} \\
\hline Mean \pm SD & $374.16 \pm 282.77$ & $16.39 \pm 3.41$ & & \\
\hline Median (range) & $462(20-761)$ & $16.54(9.45-23)$ & & \\
\hline \multicolumn{3}{|l|}{ MCP-1 (ng/ml) } & \multirow{3}{*}{$-5.440 \bullet$} & \multirow{3}{*}{$<0.001$} \\
\hline Mean \pm SD & $0.703 \pm 0.360$ & $0.318 \pm 0.064$ & & \\
\hline Median (range) & $0.590(0.340-1.640)$ & $0.330(0.180-0.390)$ & & \\
\hline
\end{tabular}


Table (3): Correlation between AFP, MCP-1 and studied parameters in HCC patients

\begin{tabular}{|l|c|c|c|c|}
\hline \multirow{2}{*}{ HCC Patients } & \multicolumn{2}{c|}{ MCP-1 (ng/mL) } & \multicolumn{2}{c|}{ AFP (ng/mL) } \\
\cline { 2 - 5 } & $\mathbf{r}$ & P-value & r & P-value \\
\hline Age (years) & +0.114 & 0.557 & +0.009 & 0.961 \\
\hline Tumor size (cm) & +0.737 & $<0.001$ & +0.403 & 0.030 \\
\hline Hemoglobin (gm/dl) & -0.035 & 0.858 & +0.222 & 0.246 \\
\hline Platelet count (x10//mm $\mathbf{3}$ ) & -0.073 & 0.707 & -0.029 & 0.882 \\
\hline Total serum bilirubin (mg/dl) & +0.229 & 0.232 & -0.306 & 0.107 \\
\hline AST (U/L) & +0.370 & $0.048(\mathrm{~S})$ & +0.124 & 0.522 \\
\hline ALT (U/L) & +0.257 & $0.178(\mathrm{NS})$ & +0.066 & 0.732 \\
\hline Albumin (gm/dl) & -0.166 & $0.391(\mathrm{NS})$ & +0.071 & 0.716 \\
\hline PC & +0.424 & $0.022(\mathrm{~S})$ & -0.181 & 0.346 \\
\hline Creatinine (mg/dl) & +0.211 & $0.272(\mathrm{NS})$ & -0.331 & 0.079 \\
\hline Urea (mg/dl) & +0.344 & $0.068(\mathrm{NS})$ & -0.200 & 0.298 \\
\hline AFP (ng/mL) & +0.173 & $0.370(\mathrm{NS})$ & --- & -- \\
\hline (ng/mL) & --- & --- & +0.173 & 0.370 \\
\hline
\end{tabular}

r: Spearman's correleation coefficient, $\mathrm{P}<0.05$; significant and $\mathrm{P}<0.001$; highly significant. PC; Prothrombin concentration, AFP;alphafetoprotein; AST; Aspartate transaminase, ALT; Alanine transaminase, MCP-1; Monocyte Chemoattractant Protein-1

Table (4): Diagnostic performance of MCP-1, AFP and both in prediction of HCC; ROC curve Analysis

\begin{tabular}{|c|c|c|c|c|c|c|}
\hline $\begin{array}{l}\text { Cut-off } \\
\text { values }\end{array}$ & $\begin{array}{c}\text { Sensitivity } \\
(\%) \\
(95 \% \mathrm{CI})\end{array}$ & $\begin{array}{c}\text { Specificity } \\
(\%) \\
(95 \% \mathrm{CI})\end{array}$ & $\begin{array}{l}\text { PPV \% } \\
\text { (95\% } \\
\text { CI) }\end{array}$ & $\begin{array}{l}\text { NPV \% } \\
(95 \% \text { CI })\end{array}$ & $\begin{array}{l}\text { Accuracy } \\
(95 \% \text { CI })\end{array}$ & $\underset{(95 \% \text { CI })}{\text { AUROC }}$ \\
\hline $\begin{array}{c}* \mathrm{MCP}-1 \\
>0.390 \\
\text { ng/ml }\end{array}$ & $\begin{array}{c}75.8 \% \\
(56.5-89.7)\end{array}$ & $\begin{array}{c}88.3 \% \\
(88.1-100)\end{array}$ & $\begin{array}{l}100 \% \\
(84.6- \\
100)\end{array}$ & $\begin{array}{c}80.6 \% \\
(64-91.8)\end{array}$ & $\begin{array}{c}87.9 \% \\
(72.3-94.9)\end{array}$ & $\begin{array}{l}0.916 \\
(0.812- \\
0.972)\end{array}$ \\
\hline $\begin{array}{c}* * A F P \\
>20 \\
\text { ng/ml }\end{array}$ & $\begin{array}{c}86.5 \% \\
(79.2-99.9)\end{array}$ & $\begin{array}{c}96.4 \% \\
(88.1-100)\end{array}$ & $\begin{array}{c}100 \% \\
(87.7- \\
100)\end{array}$ & $\begin{array}{c}90.7 \% \\
(79.8-99.9)\end{array}$ & $\begin{array}{c}95.3 \% \\
(82.2-100)\end{array}$ & $\begin{array}{l}0.924 \\
(0.911- \\
1.000)\end{array}$ \\
\hline $\begin{array}{c}* * *^{*} \text { MCP-1 } \\
+ \text { AFP } \\
>\text { 23.390 } \\
\text { ng/ml }\end{array}$ & $\begin{array}{c}96.5 \% \\
(82.2-99.9)\end{array}$ & $\begin{array}{c}100 \% \\
(88.1-100)\end{array}$ & $\begin{array}{c}100 \% \\
(87.7- \\
100)\end{array}$ & $\begin{array}{c}96.7 \% \\
(82.8-99.9)\end{array}$ & $\begin{array}{c}98.3 \% \\
(85.2-100)\end{array}$ & $\begin{array}{l}0.995 \\
(0.928- \\
1.000)\end{array}$ \\
\hline
\end{tabular}

* $\mathrm{SE}=0.035 ; \mathrm{Z}=11.708 ; \mathrm{p}<0.001$

$* * * \mathrm{SE}=0.006 ; \mathrm{Z}=76.779, \mathrm{p}<0.001$

$\mathrm{p}<0.05$; significant and $\mathrm{p}<0.001$; highly significant

** $\mathrm{SE}=0.005 ; \mathrm{Z}=85.042 ; \mathrm{p}<0.001$

NPV: Negative Predictive Value

PPV: Positive Predictive Value

95\%CI: 95\% Confidence Interval

AUROC: Area Under Receiver Operating Characteristic curve

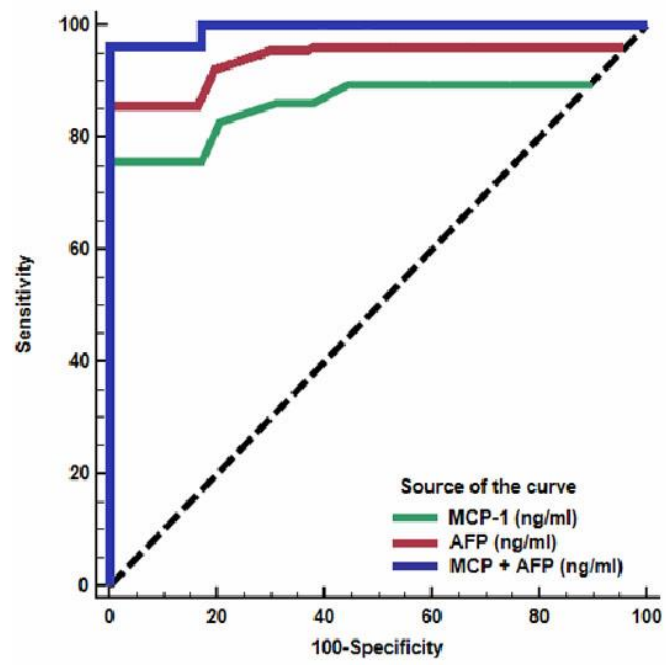

Fig. (1): Receiver operating characteristic (ROC) curve of MCP-1 and AFP as a predictor for HCC. 


\section{DISCUSSION}

The role of AFP in the diagnosis of $\mathrm{HCC}$ is controversial. Most studies used different cut-off values for AFP which gave low sensitivity and specificity especially with small $\mathrm{HCC}(<5 \mathrm{~cm})$ and confirmed the inadequacy of using AFP alone for HCC diagnosis $[\mathbf{1 2 , 1 3}$. Thus other biomarkers for better detection of HCC were investigated $[\mathbf{1 5 , 1 6 ]}$. In this study, we investigated MCP-1, a serum biomarker, alone or in combination with AFP for detection of HCC. MCP-1 is a potent chemokine which plays a role in the recruitment of monocytes to sites of injury and infection. Association between MCP-1 and liver damage has been implicated due to the findings that hepatic stellate cells are major source of MCP-1 [18,19]. Different studies showed that MCP-1 expression occurs during severe acute liver injury with significant elevation of its level [20,21,22].

Furthermore, studies showed that MCP-1 expression is associated with $\mathrm{HCC}$ development and progression[23]. HCC cells and cancerassociated fibroblasts are prominent contributors of MCP-1, regardless of whether the liver is cirrhotic or not $[\mathbf{2 4 , 2 5 ]}$.

According to the demographic data, it was found that most of patients were older in HCC group (57.86 \pm 5.73$)$ with statistical significant difference among both studied groups $(\mathrm{P}=0.003)$. These results meet the results of Velazquez et al. which found that cirrhotic patients older than 54 years have four times higher risk for developing HCC than younger ones[12]. Furthermore, it was found that $82.8 \%$ of our HCC patients were males with no statistically significant difference was observed among both studied groups $(\mathrm{P}=$ 0.738). This result is consistent with El-Zayadi et al. who found that HCC is more prevalent in males than females which may be explained by differences in exposure to risk factors[3]. It has been determined that estrogens and androgens could modulate hepato-carcinogenesis and explain the higher incidence of HCC in men $[14,17]$.

Most of our HCC patients were in Child-Pugh class $\mathrm{A}(65.5 \%)$ and the remaining $34.5 \%$ were in class B while were excluded patients with ChildPugh class $C$ because they will not benefit from early diagnosis of HCC [26].Our result is in agreement with Wang et al. which stated that the majority of the HCC patients were in Child-Pugh class A (98.4\%)[27]. Also, our results showed that there was statistically significant higher values of both AFP and MCP-1 (374.16 \pm 282.77 and $0.703 \pm 0.360$ respectively, $\mathrm{P}<0.001)$ among patients of HCC group. Furthermore, no correlation were found between serum concentrations of AFP and MCP-1 with laboratory parameters including liver function parameters, while there was statistically significant correlation between tumor size (in $\mathrm{cm}$ ) and both MCP-1 ( $\mathrm{P}<0.001)$ and AFP $(\mathrm{P}=0.030)$. This is consistent with Wang and his colleagues which mentioned that no significant correlation between serum MCP-1 level with the other liver function parameters, therefore MCP-1 levels in the HCC patients were likely to be predominantly expressed by HCC tumors and the HCC-associated cells [27].

We investigated the diagnostic performance of both serum MCP-1and serum AFP, alone or in combination, by performing ROC analysis and comparing the resulting AUROC. Our results showed that MCP-1 at a cut-off value $>0.390$ $\mathrm{ng} / \mathrm{ml}$ has a sensitivity of $75.8 \%$ and specificity of $88.3 \%$ with AUROC 0.916 ; But AFP at a cutoff value $>20 \mathrm{ng} / \mathrm{ml}$ has a sensitivity of $86.5 \%$ and specificity of $96.4 \%$ with AUROC 0.924, while combined (AFP+MCP-1) at a cut-off value $>23.390 \mathrm{ng} / \mathrm{ml}$ has a higher sensitivity $(96.5 \%)$ specificity of $100 \%$ with AUROC 0.995

These results agree with the results of Wang et al. which found that AUROC of MCP-1 was 0.823 , AUROC of AFP was 0.942 and the AUROC of combined (AFP+MCP-1) was 0.974 [27]. So Combined (AFP+MCP-1) showed higher diagnostic ability than MCP-1 alone or AFP alone.

\section{CONCLUSION}

Monocyte Chemoattractant Protein -1 (MCP-1) can be identified as an adjuvant biomarker for HCC detection. Combined (AFP+MCP-1) showed higher diagnostic ability than MCP-1 alone or AFP alone in HCC detection.

Funding: None.

Conflicts of interest: None.

Ethical approval: A written informed consent was taken from all included patients, and the study was approved by the Ethical Committee of Faculty of Medicine, Zagazig University. 


\section{REFERENCES}

1. Jemal A, Bray F, Center M, Ferlay J, Ward E, Forman D. Global cancer statistics. CA Cancer J Clin. 2011, 61: 69-90.

2. Siegel R, Naishadham D, Jemal A. Cancer statistics, 2012. CA Cancer J Clin. 2012, 62: 10-29.

3. El-Zayadi AR, Badran HM, Barakat EM, Attia Mel-D, Shawky S, Mohamed MK, et al. Hepatocellular carcinoma in Egypt: a single center study over a decade. World J Gastroenterol. 2005, 11: 5193-5198.

4. Altekruse SF, McGlynn KA, Reichman ME. Hepatocellular carcinoma incidence, mortality, and survival trends in the United States from 1975 to 2005. J Clin Oncol. 2009, 27: 1485-1491.

5. Maringhini A, Cottone M, Sciarrino E, Marceno MP, La Seta F, Fusco G, et al. Ultrasonography and alpha-fetoprotein in diagnosis of hepatocellular carcinoma in cirrhosis. Dig Dis Sci. 1988,33: 47-51.

6. Oka H, Saito A, Ito K, Kumada T, Satomura S, Kasugai $\mathrm{H}$, et al. Multicenter prospective analysis of newly diagnosed hepatocellularcarcinoma with respect to the percentage of Lens culinaris agglutinin-reactive alpha-fetoprotein.J Gastroenterol Hepatol. 2001, 16: 1378-1383.

7. Ikoma J, Kaito M, Ishihara T, Nakagawa N, Kamei A, Fujita N, et al. Early diagnosis of hepatocellular carcinoma using asensitive assay for serum des-gamma-carboxy prothrombin: aprospective study. Hepatogastroenterology 2002, 49: 235-238.

8. Zhao YJ, Ju Q, Li GC. Tumor markers for hepatocellular carcinoma. Mol Clin Oncol. 2013, 1: 593-598.

9. Colli A, Fraquelli M, Casazza G, Massironi S, Colucci A, Conte D, et al.Accuracy of ultrasonography, spiral CT, magnetic resonance, and alpha-fetoprotein in diagnosing hepatocellular carcinoma: a systematic review. Am J Gastroenterol. 2006, 101: 513-523.

10. Deshmane SL, Kremley S, Amini S, Sawaya BE. Monocyte chemoattractant protein-1 (MCP-1): An overview. J Interferon Cytokine Res. 2009, 29: 313-326.

11. Carr MW, Roth SJ, Luther E, Rose SS, Springer T. Monocyte chemoattractant protein 1 acts as a T-lymphocyte chemoattractant. Proc Natl Acad Sci USA. 1994, 91:3652-3656.

12. Velazquez RF, Rodriguez M, Navascues CA, Linares A, Perez R, Sotorrios NG, et al. Prospective analysis of risk factors for hepatocellular carcinoma in patient with liver cirrhosis. Hepatology. 2003, 37: 520-527.

13. Omata M, Lesmana LA, Tateishi R, Chen PJ, Lin SM, Yoshida H, et al. Asian Pacific Association for the Study of the Liver consensus recommendations on hepatocellular carcinoma. Hepatol Int. 2010, 4: 439-474.
14. Soresi M, Magliarisi C, Campagna P, Leto G, Bonfissuto G, Riili A, et al. Usefulness of alphafetoprotein in the diagnosis of hepatocellular carcinoma. Anticancer Res. 2003, 23: 1747-1753.

15. Marrero JA, Su GL, Wei W, Emick D, Conjeevaram HS, Fontana RJ, et al. Des-gamma carboxyprothrombin can differentiate hepatocellular carcinoma from non-malignant chronic liver disease in american patients. Hepatology. 2003, 37: 1114-1121.

16. Kobayashi M, Kuroiwa T, Suda T, Tamura Y, Kawai H, Igarashi M, Igarashi M, et al. Fucosylated fraction of alpha-fetoprotein, L3, as a useful prognostic factor in patients with hepatocellular carcinoma with special reference to low concentrations of serum alpha-fetoprotein. Hepatol Res. 2007, 37: 914-922.

17. Nagasue N, Ogawa Y, Yukaya H, Ohta N, Ito A. Serum levels of estrogens and testosterone in cirrhotic men with and without hepatocellular carcinoma. Gastroenterology.1985, 88: 768-772.

18. Friedman SL. Molecular regulation of hepatic fibrosis, an integrated cellular response to tissue injury. J Biol Chem. 2000, 275: 2247-2250.

19. Marra F, DeFranco R, Grappone C, Milani S, Pastacaldi S, Pinzani, $M$, et al. Increased expression of monocyte chemotactic protein-1 during active hepatic fibrogenesis: correlation with monocyte infiltration. Am J Pathol. 1998, 152: 423-430.

20. Fisher NC, Neil DA, Williams A, Adams DH. Serum concentrations and peripheral secretion of the beta chemokines monocyte chemoattractant protein 1 and macrophage inflammatory protein 1alpha in alcoholic liver disease. Gut. 1999, 45: 416-420.

21. Antoniades CG, Quaglia A, Taams LS, Mitry RR, Hussain M, Abeles R, et al. Source and characterization of hepatic macrophages in acetaminophen-induced acute liver failure in humans. Hepatology. 2012, 56: 735-746.

22. Degre D, Lemmers A, Gustot T, Ouziel R, Trepo E, Demetter P, et al. Hepatic expression of CCL2 in alcoholic liver disease is associated with disease severity and neutrophil infiltrates. Clin Exp Immunol. 2012, 169: 302-310.

23. Dagouassat M, Suffee N, Hlawaty H, Haddad O, Charni F, Laguillier, C, et al. Monocyte chemoattractant protein-1 (MCP-1)/CCL2 secreted by hepatic myofibroblasts promotes migration and invasion of human hepatoma cells. Int J Cancer. 2010, 126: 1095-1108.

24. Yoong KF, Afford SC, Jones R, Aujla P, Qin S, Price $\mathrm{K}$, et al. Expression and function of CXC and $\mathrm{CC}$ chemokines in human malignant liver tumors: a role for human monokine induced by gamma-interferon in lymphocyte recruitment to hepatocellular carcinoma. Hepatology. 1999, 30: 100-111. 
25. Lin ZY, Chuang YH, Chuang WL. Cancerassociated fibroblasts upregulate CCL2, CCL26, IL6 and LOXL2 genes related to promotion of cancer progression in hepatocellular carcinoma cells. Biomed Pharmacother. 2012, 66: 525-529.

26. Bruix J, Sherman M, Llovet JM, Beaugrand M, Lencioni R, Burroughs AK, et al. Clinical management of hepatocellular carcinoma. Conclusions of the Barcelona-2000 EASL Conference. J Hepatol. 2001, 35: 421-430.
27. Wang WW, Ang SF, Kumar R, Heah C, Utama A, Tania NP, et al. Identification of serum monocyte chemoattractant protein-1 and prolactin as potential tumor markers in hepatocellular carcinoma. PLoS One. 2013, 8: e68904.

Peer reviewer: Tarik Zaher, Professor of Tropical Medicine and Hepatogastroenterology, Faculty of Medicine, Zagazig University, Egypt. Editors: Sahar El-Nemr, Mohamad Emara, Assistant Professors of Tropical Medicine and Hepatogastroenterology, Faculty of Medicine, Zagazig University, Egypt. 